\title{
Karakteristik Wanita dengan Keluhan Masa Menopause di Wilayah Kerja Puskesmas Rejosari
}

\section{Characteristics of Women with Menopause Complaint in The Work Area Health Center Rejosari}

\author{
Liva Maita, Nurlisis, Risa Pitriani
}

\section{Program Studi Kebidanan Sekolah Tinggi Ilmu Kesehatan Hang Tuah Pekanbaru}

\begin{abstract}
ABSTRAK
Menopause merupakan fase terakhir dimana perdarahan haid seorang wanita berhenti sama sekali. Pada usia 50 tahun, perempuan memasuki masa menopause sehingga terjadi penurunan atau hilangnya hormon estrogen yang menyebabkan perempuan mengalami keluhan atau gangguan yang seringkali mengganggu aktivitas sehari-hari bahkan dapat menurunkan kualitas hidupnya. Penelitian ini dilakukan untuk mengetahui karakteristik wanita yang mengalami keluhan masa menopause di Puskesmas Rejosari. Penelitian ini bersifat kuantitatif analitik dengan desain cross sectional. Populasi dalam penelitian ini adalah seluruh wanita usia 45-59 tahun yang berkunjung di puskesmas Rejosari yang berjumlah 100 orang. Data yang digunakan merupakan data primer. Analisis yang digunakan analisis bivariat untuk mengetahui adanya hubungan karakteristik wanita dengan keluhan masa menopause. Hasil penelitian didapatkan umur wanita dan kondisi haid berhubungan dengan keluhan masa menopause sedangkan paritas, alat kontrasepsi, Indeks Masa Tubuh, pendidikan, pekerjaan, status pernikahan, dan pendapatan tidak berhubungan dengan keluhan masa menopause. Diharapkan kepada Puskesmas Rejosari untuk dapat memberikan penyuluhan tentang gizi yang baik menjelang menopause dan persiapan menghadapi menopause melalui pelaksanaan senam lansia secara rutin.
\end{abstract}

Kata kunci : umur, kondisi haid, keluhan menopause.

\section{ABSTRACT}

Menopause is the last phase of a woman's menstrual bleeding which stopped altogether. At the age of 50 years, menopausal women that happens a decrease or loss of estrogen hormones that cause women experience a complaints or disorders that often interferes with daily activities can even lower your quality of life. This research was conducted to find out the characteristics of women who experience menopausal complaints in Puskesmas Rejosari. This research is quantitative analytic with cross sectional design. The population in this study are all women aged 45-59 years who visited clinics in Rejosari totalling 100 people. The Data used is primary data. The analysis used to determine the presence of bivariat analysis relationship characteristics of women with menopausal complaints. Result of research got woman age and menstrual condition relate to sigh a period of menopause while parity, intrauterine device, Make an index to A period of Body, education, work, nuptials status, and earnings not relate to sigh a period to menopause. Expected to health centers to provide counseling Rejosari about good nutrition before menopause and preparation for menopause gymnastics through the implementation of the elderly on a regular basis.

Keywords: age, conditions of menstruation, menopausal complaints.

\section{PENDAHULUAN}

Menopause merupakan fase terakhir dimana perdarahan haid seorang wanita berhenti sama sekali (Yatim, 2001). Pada usia 50 tahun, perempuan memasuki masa menopause sehingga terjadi penurunan atau hilangnya hormon estrogen yang menyebabkan perempuan mengalami keluhan atau gangguan yang seringkali mengganggu aktivitas sehari-hari bahkan dapat menurunkan kualitas hidupnya. Sindrom menopause dialami oleh banyak wanita hampir di seluruh dunia. Sekitar 70\%-80\% wanita Eropa, $60 \%$ wanita di Amerika, $57 \%$ di Malaysia, 18\% di Cina, dan 10\% di Jepang (Baziad, 2003).
Menurut Nissa (2004) yang dikutip dalam Marlina (2010), Respon wanita terhadap berat tidaknya keluhan masa menopause tergantung dari karakteristik wanita menopause tersebut. Keluhan pada saat menopause dipengaruhi oleh kondisi haid, jumlah anak (paritas), umur menopause, alat kontrasepsi hormonal, Index Masa Tubuh (IMT), pendidikan, pekerjaan, status pernikahan, dan sosial ekonomi.

Ditinjau dari rekapan laporan kegiatan lansia di kabupaten/kota triwulan ke-4 (Oktober - Desember 2010) Dinas Kesehatan Kota Pekanbaru, dari 19 Puskesmas yang ada di Pekanbaru Puskesmas Rejosari menempati urutan pertama yang memiliki jumlah lansia terbanyak dengan jumlah lansia yang dibina 818 
orang Setelah dilakukan studi pendahuluan di puskesmas rejosari, dengan mewawancarai 15 orang wanita usia 45-59 tahun, 10 diantaranya mengatakan mengalami keluhan menopause diantaranya sakit berhubungan seksual dan hot fluses.

Dengan memahami tentang masalah yang terjadi seputar menopause, diharapkan para perempuan dapat melakukan upaya pencegahan sedini mungkin siap memasuki masa menopause tanpa harus mengalami keluhan-keluhan yang seharusnya tidak perlu terjadi.

\section{METODE}

Penelitian ini bersifat kuantitatif analitik dengan desain cross sectional. Populasi dalam penelitian ini adalah seluruh wanita usia 45-59 tahun yang berkunjung di puskesmas Rejosari sebanyak 100 orang. Lokasi Penelitian ini di Puskesmas Rejosari. Waktu Penelitian Bulan September - Desember 2011, sumber data berupa data primer dengan wawancara menggunakan kuesioner. Analisis data dilakukan secara univariat dan bivariat. Kondisi haid tidak normal apabila dalam satu tahun tidak mengalami haid.

\section{HASIL}

Hasil analisis univariat dari 100 responden yang mengalami keluhan pada masa menoupose sebanyak $70 \%$, kondisi haid normal $89 \%$, tidak obesitas $88 \%$, yang menggunakan alat kontrasepsi 86 $\%$, pendidikan rendah $81 \%$, umur $\geq 50$ tahun sebanyak $78 \%$, tidak bekerja $68 \%$, yang menikah 63 $\%$, pendapatan tinggi $62 \%$, paritas sedikit $54 \%$.

\section{Analisis Bivariat}

Tabel 1 menunjukkan bahwa semua variabel independen memiliki hubungan yang signifikan terhadap karakteristik wanita yang mengalami keluhan menopause yaitu kondisi haid dan umur. Wanita yang memiliki umur $\geq 50$ tahun berisiko memiliki keluhan masa menopause 3 kali dibandingkan dengan ibu yang memiliki umur $<50$ tahun (OR 3,38 CI 95\% 1,37$8,33)$. Wanita yang memiliki kondisi tidak normal berisiko memiliki keluhan masa menopasuse 0,2 kali dibandingkan dengan ibu yang memiliki kondisi haid normal (28-35 hari) (OR 0,2 CI 95\% 0,05-0,74)

Tabel 1

Resume Hasil Analisis Bivariat

\begin{tabular}{|c|c|c|c|c|c|c|}
\hline \multirow{3}{*}{ Variabel } & \multicolumn{4}{|c|}{ Keluhan Masa Menopause } & \multirow{3}{*}{$\begin{array}{c}(P \\
\text { Value })\end{array}$} & \multirow{3}{*}{$\begin{array}{c}\text { OR/ } \\
\text { (CI 95\%) }\end{array}$} \\
\hline & \multicolumn{2}{|c|}{ Ada Keluhan } & \multicolumn{2}{|c|}{$\begin{array}{l}\text { Tidak } \\
\text { Keluhan }\end{array}$} & & \\
\hline & $\mathbf{N}$ & $\%$ & $\mathbf{N}$ & $\%$ & & \\
\hline Kondisi Haid & & & & & \multirow{3}{*}{0,02} & \\
\hline Tidak normal & 4 & 5,7 & 7 & 23,3 & & 0,2 \\
\hline Normal & 66 & 94,3 & 23 & 76,6 & & $(0,05-0,74)$ \\
\hline \multicolumn{7}{|l|}{ Paritas } \\
\hline Sedikit $(<2)$ & 34 & 48,6 & 20 & 66,7 & \multirow[t]{2}{*}{0,14} & 0,4 \\
\hline Banyak $(\geq 2)$ & 36 & 51,4 & 10 & 33,3 & & $(0,19-1,15)$ \\
\hline \multicolumn{5}{|l|}{ Umur Menopause } & \multirow{3}{*}{0,01} & \\
\hline$\geq 50$ tahun & 44 & 62,9 & 10 & 33,3 & & 3,38 \\
\hline$<50$ tahun & 26 & 37,1 & 20 & 66,7 & & $(1,37-8,33)$ \\
\hline \multicolumn{7}{|l|}{ Alat kontrasepsi } \\
\hline Kontrasepsi Hormonal & 65 & 65 & 21 & 70,0 & \multirow[t]{2}{*}{0,07} & 5,57 \\
\hline Tidak Kontrasepsi Hormonal & 5 & 7,1 & 9 & 30,0 & & $(1,68-18,47)$ \\
\hline \multicolumn{7}{|l|}{ Pendidikan } \\
\hline Rendah (SD-SMP) & 60 & 85,7 & 21 & 70 & \multirow[t]{2}{*}{0,11} & 2,57 \\
\hline Tinggi (SMA-PT) & 10 & 14,3 & 9 & 30 & & $(0,91-7,19)$ \\
\hline \multicolumn{7}{|l|}{ IMT } \\
\hline Obesiatas $(>23)$ & 8 & 11,4 & 4 & 13,3 & \multirow[t]{2}{*}{1,00} & 0,83 \\
\hline Tidak Obesitas $(\leq 23)$ & 62 & 88,6 & 26 & 86,7 & & $(0,23-3,03)$ \\
\hline \multicolumn{7}{|l|}{ Pekerjaan } \\
\hline Tidak bekerja & 43 & 61,4 & 25 & 83,3 & \multirow[t]{2}{*}{0,05} & 0,31 \\
\hline Bekerja & 27 & 38,6 & 5 & 16,7 & & $(0,10-0,93)$ \\
\hline \multicolumn{7}{|l|}{ Status pernikahan } \\
\hline Janda & 24 & 37,0 & 13 & 43,4 & \multirow[t]{2}{*}{0,52} & 0,68 \\
\hline Menikah & 46 & 65,7 & 17 & 56,7 & & $(0,28-1,63)$ \\
\hline \multicolumn{5}{|l|}{ Pendapatan } & \multirow{3}{*}{0,52} & \\
\hline Rendah $(<1.250 .000)$ & 24 & 34,5 & 14 & 46,7 & & 0,59 \\
\hline Tinggi $(\geq 1.250 .000)$ & 46 & 65,7 & 16 & 53,3 & & $(0,25-1,42)$ \\
\hline
\end{tabular}




\section{PEMBAHASAN}

\section{Hubungan Umur Menopause dengan Keluhan Masa Menopause}

Berdasarkan Hasil uji statistik didapatkan nilai $p$ Value $=0,01$ lebih kecil dari $\alpha=0,05$ berarti ada hubungan umur menopause dengan keluhan masa Menopause. Analisis keeratan dua variabel OR 3,38 CI 95\% (1,37-8,33). Umur seseorang berpengaruh terhadap kesiapan seseorang menghadapi keluhan menopause. Semakin bertambah usia, maka semakin siap wanita menghadapi keluhan menopause.

Wanita yang mengalami menarche cepat akan mengalami menopause yang lambat. Umumnya menopause usia 40-50 tahun dan masa premenopause 3-4 tahun sehingga gejala-gejala ketakutan akan ringan sekali dan hampir tidak terasa. Sedangkan menopause usia $\geq 50$ usia meraka akan mengalami masa premenoupose sekitar 6 bulan sampai 1 tahun sehingga mereka belum siap beradaptasi dengan perubahan yang terjadi dan belum mampu mengontrol keluhan yang muncul dengan sedikit masalah dalam dirinya Mackenzie yang dikutip dalam Pertikasari (2003).

Berdasarkan hasil penelitian Masruroh (2012) didapatkan ada hubungan antara riwayat penggunaan kontrasepsi hormonal dengan usia menopause. Semakin lama memasuki usia menopasue maka keluhan yang dialami akibat penggunaan kontrasepsi akan semakin panjang.

Hal ini tentunya bertolak belakang dari hasil penelitian, yang dimana wanita yang umur $\geq 50$ tahun memiliki keluhan dibandingkan umur $<50$ tahun. Hal ini dikarenakan kurangnya informasi dan pengetahuan tentang menopause yang diberikan kepada ibu.

\section{Hubungan Kondisi Haid dengan Keluhan Masa Menopause}

Berdasarkan Hasil uji statistik didapatkan nilai $p$ Value 0,02 lebih kecil dari $\alpha=0,05$ berarti ada hubungan Kondisi Haid dengan Keluhan Masa Menopause. Menurut Supriyadi dalam Budiman (2008) kondisi haid yang tidak normal dan tidak teratur sebelum menopause akan berpengaruh ketika seseorang memasuki masa menopause hal ini dikarenakan ovarium mengalami penurunan fungsi dan ukuran disebabkan tidak tembusnya selaput lendir rahim akibat rendahnya hormon esterogen dan ketidakseimbangan hormon progesteron sehingga terjadi pembagian haid menjadi lebih sedikit, jarang bahkan siklus haid mulai terganggu yang disebut masa premenopause yang berlangsung 4-5 tahun.

Hutabarat dalam Budiman (2008) yang mengatakan bahwa ketidakteraturan siklus haid (dismenorhoe/nyeri haid, dari jumlah darah yang keluar dan waktu menstruasi) pada masa pramenopause akan berpengaruh ketika seseorang memasuki masa menopause.
Hasil penelitian ini bertolak belakang dengan hasil penelitian Desi (2007) tentang hubungan karakteristik demografi dan umur saat menopause dengan keluhan saat menopause di kalimantan barat, dimana tidak terdapat hubungan kondisi haid dengan masa menopause $\mathrm{p}$ value $>0,05$.

Perbedaan hasil penelitian ini disebabkan rerata responden memiliki kondisi haid normal tetapi banyak mengalami keluhan masa menopause. Seharusnya kondisi haid yang tidak normal yang mengalami keluhan masa menopause. Hal ini dikarenakan populasi yang menjadi sampel dalam penelitian ini bersifat homogen.

\section{KESIMPULAN}

Berdasarkan hasil penelitian yang telah dilaksanakan di Wilayah Kerja Puskesmas Rejosari Pekanbaru dapat diambil kesimpulan sebagai berikut yaitu Terdapat hubungan antara kondisi haid dan umur dengan keluhan masa menopause di Wilayah Kerja Puskesmas Rejosari Pekanbaru tahun 2011. Tidak terdapat hubungan antara paritas, alat kontrasepsi, IMT, pendidikan, pekerjaan, status pernikahan dan pendapatan dengan keluhan masa menopause di Wilayah Kerja Puskesmas Rejosari Pekanbaru tahun 2011.

\section{SARAN}

Berdasarkan hasil penelitian diatas, terdapat beberapa saran dari peneliti yaitu Meningkatkan penyuluhan tentang gizi yang baik untuk menopause dan pelaksanaan senam lansia rutin.

\section{DAFTAR PUSTAKA}

Baziad, A. (2003). Menopause dan Andropause. Jakarta: YBPSP.

Budiman, A. (2008). Menopause, (http://digilib.unsri.ac.id/download/Cpd pasca menopause.pdf, diakses 14 Februari 2011).

Desi (2007). Hubungan karakteristik demografi dan umur saat menopause dengan keluhan saat menopause.Skripsi. Kalimantan barat.

Dinas Kesehatan Kota Pekanbaru. (2010). Rekapan Laporan Kegiatan Lansia di Kabupaten/Kota Pekanbaru Triwulan Ke-4.

Marlina, H. (2010). Hubungan Karakteristik Wanita dengan Keluhan Masa Menopause di Posbindu Sri Meranti Kerja Puskesmas Rejosari. Skripsi tidak diterbitan. Program Sarjana IKM STIKES HANGTUAH Pekanbaru, Pekanbaru.

Masruroh.(2012). Hubungan antara kontrasepsi hormonal dengan usia menopause. Universitas darul ulum jombang.KTI. Jombang. 
Pertikasari, S. (2003). Pengaruh Umur, Status Perkawinan, Pendidikan, Pekerjaan, dan Pengetahuan Terhadap Sikap Wanita Dalam Menghadapi Menopause Kelurahan Pacar
Kembang, Kecamatan Tambak Sari Surabaya. Universitas Airlangga, Surabaya.

Yatim, F. (2001). Haid Tidak Wajar dan Menopause. Jakarta: Pustaka Populer Obor. 